\title{
Exchange Rate and Inflation Dynamics
}

\author{
EATZAZ AHMAD and SAIMA AHMED ALI
}

This paper studies simultaneous determination of nominal exchange rate and domestic price level in Pakistan. The estimated model contains sufficient built-in dynamics to trace the pattern and speed of adjustment in the two variables in response to temporary or permanent shocks. The two domestic shocks considered in the paper are monetary and real shocks, while the three external shocks considered are import price, export price and foreign exchange reserves shocks.

The study finds that the impact period effects of temporary shock on price level and exchange rate are divergent, while the long run effects are convergent. This means that, while purchasing power parity does not hold in the short run, there is a tendency in the system to regain relative parity in the long run. Further more continuation of shocks can produce a persistent but non-accelerating divergence between inflation rate and the rate of devaluation. Therefore the parity holds in a weaker sense, that is for the marginal fluctuations in the rates of changes in price level and exchange rate over time. It is also observed that the direction of temporary disparity between the rates of inflation and devaluation depends crucially on the origin of the shock. The shocks with direct effect on price level (exchange rate) have more pronounced effects on the rate of inflation (devaluation). Finally, the relationship between price level and exchange rate is not unidirectional, though the short run effect of devaluation on inflation is smaller than the effect of inflation on devaluation. Since movements in exchange rate are mostly driven by price inflation, the practice of using exchange rate as an independent instrument is not sustainable in the presence of inflation. From policy perspective both the inflation and exchange rate could be considered as interrelated targets while focusing on the instruments that are in effective control of policy-makers, such as money supply.

\section{INTRODUCTION}

The theory of purchasing power parity (PPP) asserts that under free international trade, perfect information and freely floating exchange rate the prices of traded goods, when expressed in a common currency, are equalised across two countries. While at the macro level the theory predicts a precise relationship between nominal exchange rate and domestic and world price levels, there are more than one

Eatzaz Ahmad and Saima Ahmed Ali are respectively Professor and Graduate Student at Department of Economics, Quaid-i-Azam University, Islamabad. 
ways to express the PPP equation. In its strict version PPP is supposed to mean that the nominal exchange rate is equal to the ratio of domestic price level to the world price level and, therefore, the real exchange rate (RER) is equal to one. A weaker version of PPP, known as relative PPP, postulates that the changes in nominal exchange rate are proportional to the changes in the ratio between domestic and world price levels to yield a constant RER. ${ }^{1}$

Empirical evidence has shown time and again that in the short run PPP does not hold [see, for example, Cooper (1994); Crowder (1992); Krugman and Obstfield (1992) and Nachane and Chrissanthaki (1991)]. Therefore one of the pertinent questions that has relevance for policy-making is how quickly and perfectly do the exchange rate and general price level in an open economy respond to each other. An answer to this question would determine, for example, how far could the neutralising effects of domestic inflation on the real exchange rate be delayed when the latter is altered by currency devaluation.

There are several well-known channels through which the domestic price level responds to the changes in prices of traded goods due to currency adjustments [Sodersten and Reed (1994)]. The literature has also established that domestic inflation is a strong driving force behind the practice of currency devaluation [e.g. Sodersten and Reed (1994a)]. An understanding of these channels of adjustment is essential to trace the dynamics path through which the PPP equation could be established in the long run.

Another relevant issue is to determine how the adjustment path towards PPP equation is dependent on the source of disturbance that had placed the nominal exchange rate and/or price levels off the PPP equation. That is, how the nominal exchange rate and price level adjust over time in response to domestic and external shocks.

The recent experience of currency devaluation and price inflation in Pakistan provides an interesting case to address the above issues. A common perception is that the practice of frequent currency devaluation is the main cause of inflation in Pakistan. This would mean that the general price level in Pakistan adjusts quickly to the traded goods prices. The policy-makers, on the other hand, seem to believe that currency devaluation is inevitable to maintain competitive strength in world market because the inflation rate in Pakistan is higher than the world inflation rate.

In the light of this background, this paper aims to study for Pakistan the relationship of nominal exchange rate and domestic price level with each other and with other economic variables in a dynamic context. The price level and exchange

${ }^{1}$ For details on alternative versions of PPP theory, [see Bhatti (1996); Dornbusch (1981); Krugman and Obstfield (1992) and Isard (1983)]. Bhatti (1996) points out that the distinction between absolute and relative PPP becomes practically impossible because the domestic and world price levels are inevitably measured in relative terms by assuming unit price in some base year. 
rate are determined simultaneously in a model that contains sufficient built-in dynamics. This framework allows us to trace the pattern and speed of adjustment in price level and exchange rate in response to various shocks.

The recent empirical work in Pakistan provides consistent evidence that the domestic price level responds significantly but gradually to exchange rate devaluation [see Ahmad and Ram (1991); Bilquees (1988); Hassan and Khan (1994) and Khan and Qasim (1996)]. It has also been found that domestic inflation is the main driving force behind the primary objective of currency adjustment to maintain a competitive RER [Burney and Akhtar (1992) and Mahmood et al. (1996)]. Bhatti (1996) has found that in the long run PPP holds between Pakistan and its eight trading partners from the industrial world. But no serious attempt has yet been made to study the short run dynamics through which the price level and exchange rate move around the PPP equation as they get displaced from their long run paths. This paper attempts to fill the gap.

The paper is organised as follows. Section 2 provides the framework of analysis. Section 3 consists of data, estimation and results. A simulation exercise is done in Section 4 to trace the transitionary phase of adjustments in price level and exchange rate following different type of shocks. Finally, conclusion and policy implications are drawn in Section 5.

\section{A MODEL OF PRICE LEVEL AND EXCHANGE RATE}

Given the sustained nature of inflation in Pakistan we assume that the Monetarist model would better explain the inflationary process in Pakistan as it has been supported in recent empirical studies [see Ahmad and Ram (1991) and Khan and Qasim (1996)]. According to this approach aggregate demand in the goods market depends inversely on the quantity of money and directly on the domestic price level. Therefore denoting the price level of domestically produced goods, money supply and domestic output (real GDP) by $P_{d}, M$ and $Y$ respectively, and assuming a log-linear aggregate demand function we can solve the goods market clearing condition to yield the following equation for the equilibrium domestic price level.

$$
\log \left(P_{d}\right)=a+b \log (M)+c \log (Y), \quad b>0, c<0, \quad \ldots \quad \ldots
$$

According to the above relationship absolute values of the elasticities of price level with respect to money supply and real output may not necessarily be the same as assumed in the strict Monetarist model (that is, the quantity theory of money). The reason is that the effects of monetary expansion on aggregate expenditure would be of uniform nature, whereas changes in real output will not affect all prices in the same manner. The timing of the two effects also matters. The initial effect of monetary expansion, especially when it is not anticipated, will be small, as some of the channels through which this effect is transmitted are indirect. The effects of 
output growth, on the other hand, would be more direct, especially on the prices of those goods that experience major changes in output level.

The general price level facing the residents of a country should include prices of all the goods that are absorbed domestically. Turnovsky and Kaspura (1974) have derived the general price index as the weighted geometric average of the price levels of domestically produced and imported goods. We consider a more general index, $P$, as the weighted geometric average of the price levels of domestically produced imported and exported goods, denoted by $P_{d}, P_{m}$ and $P_{x}$ respectively. The weights are set equal to the shares of domestically produced, imported and exported goods out of gross domestic absorption, denoted by $S_{d}, S_{m}$ and $-S_{x}$ respectively. Thus we can write in natural logs:

$$
\log (P)=S_{m} \log \left(P_{m}\right)-S_{x} \log \left(P_{x}\right)+S_{d} \log \left(P_{d}\right), \quad S_{d}+S_{m}-S_{x}=1 \quad \ldots
$$

Notice that the price level of exported goods is assigned a negative weight in obtaining the general price index. The reason is that if the price level of exported goods rises then for the given general price level of domestically produced goods (that includes the prices of exported goods), the general price level in the economy (that does not include the prices of exported goods) must decrease.

Denoting the nominal exchange rate and the dollar price levels of imports and exports by $E, \Pi_{m}$ and $\Pi_{x}$ respectively, the above equation can also be written as

$$
\begin{array}{ccccc}
\log (P)=\left(S_{m}-S_{x}\right) \log (E)+S_{m} \log \left(\Pi_{m}\right)-S_{x} \log \left(\Pi_{x}\right)+S_{d} \log \left(P_{d}\right), \\
S_{d}+S_{m}-S_{x}=1 & \ldots & \ldots & \ldots & \ldots
\end{array}
$$

Substituting for $\log \left(P_{d}\right)$ from Equation (1) into (3) yields:

$$
\begin{array}{cccc}
\log (P)=S_{d} \log (V)+\left(S_{m}-S_{x}\right) \log (E)+S_{m} \log \left(\Pi_{m}\right)-S_{x} \log \left(\Pi_{x}\right) & \\
\quad+S_{d}(a+b \log (M)+c \log (Y)) & \ldots & \ldots & \ldots
\end{array}
$$

We now add further economic content to the above relationship. First notice that an increase in the prices of imported goods can further add to inflation by reducing the supply of goods domestically available as imports are reduced. Likewise an increase in the prices of exported goods can also cause inflation by stimulating exports and leaving fewer goods available for domestic use. This means that the parameters attached to the variables $\log (E), \log \left(\Pi_{m}\right)$ and $\log \left(\Pi_{x}\right)$ need to be generalised.

Equation (4) further needs to be generalised in the light of imperfect information and the way agents respond to various signals. In particular consider foreign price shocks that may come in the form of changes either in world prices or in the nominal exchange rate. The effect of a change in the nominal exchange rate, which alters the prices of all traded goods by the same proportion, is likely to be more pronounced and of uniform nature. On the other hand, the agents' response to 
changes in world prices depends on whether they perceive them in absolute or relative terms. ${ }^{2}$ It is most likely, however, that some agents will assume that the relative prices have changed. Such a belief would prompt them to alter their choices as well. Since the resulting reallocation of resources takes place gradually, it will take some time for the general price level to adjust fully to the shock. Thus in Equation (4) the coefficient of $\log (E)$ would possibly be unrelated to the coefficients of $\log \left(\Pi_{m}\right)$ and $\log \left(\Pi_{x}\right)$.

Finally, due to the above reasons and sticky expectations, the general price level might follow closely its own past trend. Past experience with time inconsistency in government policies can convince the agents to form such expectations that are based on history rather than current information. Another reason for price inertia is the existence of contracts and price controls, which can be used to minimise the inflationary effects of policies such as devaluation and credit creation that are inflationary per se.

$$
\begin{aligned}
\log (P) & =\alpha_{0}+\left(a_{p m}+a_{p x}\right) \log (E)+\alpha_{p m} \log \left(\Pi_{m}\right)+\alpha_{p x} \log \left(\Pi_{x}\right) \\
& +\alpha_{m} \log (M)+\alpha_{y} \log (Y)+\alpha_{p} \log \left(P_{-1}\right),
\end{aligned}
$$

In the above relationship the parameter $\alpha_{p m}$ is positive. The sign of $\alpha_{p x}$ is not determined. The reason is that on the one hand, an increase in the price level of exported goods reduces the general price level on account of the way the latter is defined and on the other hand it raises the general price level by reducing supply of goods in the country. The sign of $\alpha_{p m}+\alpha_{p x}$ is, however, most likely to be positive since imports in Pakistan exceed exports and, hence, the inflationary effect of devaluation through imported goods' prices is likely to dominate the uncertain effect through exported goods' prices.

For the determination of nominal exchange rate consider the PPP equation which implies that in the long-run nominal exchange rate $\mathrm{E}$ is given by

$$
\log (E)=\log (P)-\log \left(\Pi_{w}\right), \quad \ldots \quad \ldots \quad \ldots \quad \ldots \quad \ldots
$$

where $P$ is the general price level in the economy measured in domestic currency and $\Pi_{w}$ is the world price level denominated in foreign currency. If the general price level rises faster than the world price level then the real exchange rate will fall. The resulting loss in international competitiveness will reduce net exports and thereby lead to depreciation of domestic currency.

The foregoing was a long run version of PPP. Under the managed float, a country may run a surplus or deficit on the balance of payment account for some length of time by delaying the automatic adjustment mechanism. Therefore the exchange rate might not move in one to one correspondence with domestic and world

${ }^{2}$ For details on such arguments and empirical evidence, [see Kormendi and Meguire (1984) and Attfield et al. (1983)]. 
price levels. Also as a result of this deviation, the exchange rate may respond to market forces with a time lag. And, while in the strict version of PPP, the domestic and world prices are related to exchange rate symmetrically though in opposite direction, we may leave this symmetry as a testable hypothesis in our empirical model. The possibility that the pressure to adjust the exchange value of domestic currency may be different in response to equal percentage changes in the world price levels of imports and exports is also allowed for. Thus the world price level $\Pi_{w}$ can be split into the price levels of imports and exports, $\Pi_{m}$ and $\Pi_{x}$ respectively. In the light of these considerations, we generalise Equation (6) as

$$
\begin{aligned}
\log (E)= & \beta_{0}+\beta_{p} \log (P)+\beta_{\pi m} \log \left(\Pi_{m}\right)+\beta_{\pi x} \log \left(\Pi_{x}\right)+\beta_{e} \log \left(E_{-1}\right), \\
0 & <\beta_{p}<1, \quad \beta_{\pi n}<0, \quad \beta_{\pi x}<0, \quad 0<\beta_{e}<1 . \quad \ldots \quad \ldots
\end{aligned}
$$

Finally, under managed float, the central bank can intervene in the foreign exchange market in order to achieve certain balance of payments targets [see Branson (1978)]. However if the country is running a deficit in the balance of payment, the central bank could eventually run out of foreign exchange reserves. The initial outcome of falling reserves is the excess demand in foreign exchange market by the domestic portfolio holders for rebalancing. The decrease in foreign exchange reserves generates a pressure for devaluation. ${ }^{3}$ Thus we include foreign exchange reserves, denoted $F R$, in Equation (7):

$$
\begin{aligned}
\log (E) & =\beta_{0}+\beta_{p} \log (P)+\beta_{\pi m} \log \left(\Pi_{m}\right)+\beta_{\pi x} \log \left(\Pi_{x}\right)+\beta_{F R} \log (F R)+\beta_{e} \log \left(E_{-1}\right), \\
0 & <\beta_{p}<1, \quad \beta_{\pi m}<0, \quad \beta_{\pi x}<0, \quad \beta_{F R}<0, \quad 0<\beta_{E}<1 . \quad \ldots \quad \text { (8) }
\end{aligned}
$$

This completes the theoretical part of our model for the simultaneous determination of general price level and exchange rate. We now move to the empirical side.

\section{DATA, ESTIMATION AND RESULTS}

We use quarterly data for the period 1982-II to 1996-IV over which the exchange rate of Pakistani rupee has been set under managed float. The sources of data are Annual Report (State Bank of Pakistan), Monthly Statistical Bulletin (Federal Bureau of Statistics) and Statistical Bulletin (State Bank of Pakistan). The quarterly series for exchange rate is constructed by taking a weighted average for each quarter, where weights are the number of days the exchange rate assumes a particular value. The general price level is represented by Consumer Price Index. The

${ }^{3}$ Sodersten and Reed (1994) stated that under pegged exchange rate the pressure to devalue with persistent balance of payment deficit is greater than the pressure to appreciate with persistent surplus. The immediate reason is that maintaining a pegged value against deficit requires continual buying of domestic currency and depleting foreign reserves. Since foreign reserves are limited, the ability of a country to withstand downward pressure on its currency is also limited. 
world price level of imports (exports) in rupees is represented by the unit value index of imports (exports). The overall world price index (of imports and exports) is calculated as a weighted average of the import and export price indices, where the weights are the shares of imports and exports in the trade volume. To convert these indices in dollar terms, we divide them by the current exchange rate and multiply by the base period (1981-I) exchange rate: Monetary assets, following the broad definition $\mathrm{M}_{2}$, and foreign exchange reserves (in dollars) are measured at the beginning of the quarter. The quarterly GDP series is generated by applying linear interpolation on the annual GDP growth rates of GDP and imposing continuity conditions.

As a preliminary step towards the estimation of price and exchange rate Equations (5) and (8) we diagnose and remove (where found) the econometric problems common in time series data such as autocorrelation, multicollinearity and non-stationarity of regression residuals. Along our way we also examine a number of propositions that were used in Section 2 to introduce flexibility in our model.

The first round estimation revealed that the error term in the price Equation (5) is autocorrelated and that the movements in general price level have a seasonal component. On the basis of diagnostic experiments, we include in the equation the four quarter lagged price level to remove seasonality and an MA(1) process to control autocorrelation. No such problem is found in the exchange rate Equation (8). However, the results in both cases might have been eroded by multicollinearity as some parameters are insignificant despite an extremely good overall fit. To improve the quality of estimates we impose a number of restrictions on the basis of statistical tests on various generalisations introduced in Section 2.

First of all the export price variable $\log \left(\Pi_{x}\right)$ is dropped from the price equation as its effect is found to be insignificant. This means that, while an increase in the dollar price of imports significantly raises the general price level, no such effect is evident with respect to the dollar price of exports.

To test the proposition in Section 2 that the impact period effect of a given change in exchange rate on the general price level is more pronounced as compared to the effect of an equal proportional change in world price level, we apply $t$-test on the null hypothesis that the regression coefficients of $\log (P)$ and $\log \left(\Pi_{m}\right)$ are equal. The test reveals that the null hypothesis cannot be rejected even at very high level of significance. This means that the effects of an increase in the rupee price level of imports on the general price level is independent of whether its source is devaluation or an increase in the dollar price of imports. Thus we can combine exchange rate $E$ and the dollar price of imports $\Pi_{m}$ into a single variable, namely the rupee price of imports: $P_{m}=E \Pi_{m}$; therefore $\log \left(P_{m}\right)=\log (E)+\log \left(\Pi_{m}\right)$.

We then test the proposition that the pressure to devalue in response to an equal percentage decrease in the world price levels of imports and exports is the 
price levels. Also as a result of this deviation, the exchange rate may respond to market forces with a time lag. And, while in the strict version of PPP, the domestic and world prices are related to exchange rate symmetrically though in opposite direction, we may leave this symmetry as a testable hypothesis in our empirical model. The possibility that the pressure to adjust the exchange value of domestic currency may be different in response to equal percentage changes in the world price levels of imports and exports is also allowed for. Thus the world price level $\Pi_{w}$ can be split into the price levels of imports and exports, $\Pi_{m}$ and $\Pi_{x}$ respectively. In the light of these considerations, we generalise Equation (6) as

$$
\begin{aligned}
\log (E)= & \beta_{0}+\beta_{p} \log (P)+\beta_{\pi m} \log \left(\Pi_{m}\right)+\beta_{\pi x} \log \left(\Pi_{x}\right)+\beta_{e} \log \left(E_{-1}\right), \\
0 & <\beta_{p}<1, \quad \beta_{\pi m}<0, \quad \beta_{\pi x}<0, \quad 0<\beta_{e}<1 . \quad \ldots \quad \ldots
\end{aligned}
$$

Finally, under managed float, the central bank can intervene in the foreign exchange market in order to achieve certain balance of payments targets [see Branson (1978)]. However if the country is running a deficit in the balance of payment, the central bank could eventually run out of foreign exchange reserves. The initial outcome of falling reserves is the excess demand in foreign exchange market by the domestic portfolio holders for rebalancing. The decrease in foreign exchange reserves generates a pressure for devaluation. ${ }^{3}$ Thus we include foreign exchange reserves, denoted $F R$, in Equation (7):

$$
\begin{aligned}
\log (E) & =\beta_{0}+\beta_{p} \log (P)+\beta_{\pi m} \log \left(\Pi_{m}\right)+\beta_{\pi x} \log \left(\Pi_{x}\right)+\beta_{F R} \log (F R)+\beta_{e} \log \left(E_{-1}\right), \\
0 & <\beta_{p}<1, \quad \beta_{\pi m}<0, \quad \beta_{\pi x}<0, \quad \beta_{F R}<0, \quad 0<\beta_{E}<1 .
\end{aligned}
$$

This completes the theoretical part of our model for the simultaneous determination of general price level and exchange rate. We now move to the empirical side.

\section{DATA, ESTIMATION AND RESULTS}

We use quarterly data for the period 1982-II to 1996-IV over which the exchange rate of Pakistani rupee has been set under managed float. The sources of data are Annual Report (State Bank of Pakistan), Monthly Statistical Bulletin (Federal Bureau of Statistics) and Statistical Bulletin (State Bank of Pakistan). The quarterly series for exchange rate is constructed by taking a weighted average for each quarter, where weights are the number of days the exchange rate assumes a particular value. The general price level is represented by Consumer Price Index. The

${ }^{3}$ Sodersten and Reed (1994) stated that under pegged exchange rate the pressure to devalue with persistent balance of payment deficit is greater than the pressure to appreciate with persistent surplus. The immediate reason is that maintaining a pegged value against deficit requires continual buying of domestic currency and depleting foreign reserves. Since foreign reserves are limited, the ability of a country to. withstand downward pressure on its currency is also limited. 
world price level of imports (exports) in rupees is represented by the unit value index of imports (exports). The overall world price index (of imports and exports) is calculated as a weighted average of the import and export price indices, where the weights are the shares of imports and exports in the trade volume. To convert these indices in dollar terms, we divide them by the current exchange rate and multiply by the base period (1981-I) exchange rate. Monetary assets, following the broad definition $\mathbf{M}_{2}$, and foreign exchange reserves (in dollars) are measured at the beginning of the quarter. The quarterly GDP series is generated by applying linear interpolation on the annual GDP growth rates of GDP and imposing continuity conditions.

As a preliminary step towards the estimation of price and exchange rate Equations (5) and (8) we diagnose and remove (where found) the econometric problems common in time series data such as autocorrelation, multicollinearity and non-stationarity of regression residuals. Along our way we also examine a number of propositions that were used in Section 2 to introduce flexibility in our model.

The first round estimation revealed that the error term in the price Equation (5) is autocorrelated and that the movements in general price level have a seasonal component. On the basis of diagnostic experiments, we include in the equation the four quarter lagged price level to remove seasonality and an MA(1) process to control autocorrelation. No such problem is found in the exchange rate Equation (8). However, the results in both cases might have been eroded by multicollinearity as some parameters are insignificant despite an extremely good overall fit. To improve the quality of estimates we impose a number of restrictions on the basis of statistical tests on various generalisations introduced in Section 2.

First of all the export price variable $\log \left(\Pi_{x}\right)$ is dropped from the price equation as its effect is found to be insignificant. This means that, while an increase in the dollar price of imports significantly raises the general price level, no such effect is evident with respect to the dollar price of exports.

To test the proposition in Section 2 that the impact period effect of a given change in exchange rate on the general price level is more pronounced as compared to the effect of an equal proportional change in world price level, we apply $t$-test on the null hypothesis that the regression coefficients of $\log (P)$ and $\log \left(\Pi_{m}\right)$ are equal. The test reveals that the null hypothesis cannot be rejected even at very high level of significance. This means that the effects of an increase in the rupee price level of imports on the general price level is independent of whether its source is devaluation or an increase in the dollar price of imports. Thus we can combine exchange rate $E$ and the dollar price of imports $\Pi_{m}$ into a single variable, namely the rupee price of imports: $P_{m}=E \Pi_{m}$; therefore $\log \left(P_{m}\right)=\log (E)+\log \left(\Pi_{m}\right)$.

We then test the proposition that the pressure to devalue in response to an equal percentage decrease in the world price levels of imports and exports is the 
same. This means that the coefficients of the price variables $\log \left(\Pi_{m}\right)$ and $\log \left(\Pi_{x}\right)$ are equal. The $t$-value for the difference in the two regression coefficients is 0.21 , which means that the proposition cannot be rejected. This leads us to combine the price levels of imports and exports into a single variable namely the world price level $\Pi_{w}$, which is a weighted average of the two price variables, the weights being the shares of imports and exports in the volume of trade.

A final hypothesis to be tested is about the effects of domestic and world prices on the exchange rate. As mentioned in Section 2, under the strict PPP the effect of an increase in domestic price on the exchange rate would be equal to the effect of equally proportional decrease in world price level. Within our framework, this proposition can be tested by imposing the restriction that the coefficient of $\log (P)$ is equal to the negative of the coefficient of $\log \left(\Pi_{w}\right)$. The value of $t$-statistic for this restriction is 5.46, meaning that the proposition stands rejected.

After imposing the restrictions that are accepted, the two equations are reestimated and examined for cointegration by applying Augmented Dickey-Fuller (ADF) test on regression residuals. ${ }^{4}$ The test is applied with alternative options on intercept, trend and lagged first difference terms. The null hypothesis of unit root is rejected at 5 percent level for both the equations. We thus conclude that the relationships are valid for the long run. below. ${ }^{5}$

The final estimates based on Two Stage Least Squares method are reported

$$
\begin{aligned}
& \log (P)=1.591+0.149\left[\log (E)+\log \left(\Pi_{m}\right)\right]+0.067 \log (M)-0.209 \\
& (2.32 * *) \quad\left(3.45^{*}\right) \\
& \left(1.82^{* * *}\right) \\
& \log (Y)+0.506 \log \left(P_{-1}\right)+0.350 \log \left(P_{4}\right) \\
& (4.51 *)
\end{aligned}
$$

MA(1) coefficient $=0.401, R^{2}=0.9986, \quad D . W .=2.06, h=-0.40$.

$$
\begin{aligned}
& \log (E)=0.160+0.341 \log (P)-0.180 \log \left(\Pi_{w}\right)-0.013 \log (F R) \\
& \text { (0.91) }\left(4.51^{*}\right) \\
& +0.665 \log \left(E_{-1}\right) \text {; } \\
& \left(-3.45^{*}\right)
\end{aligned}
$$

$$
R^{2}=0.9952, \quad D . W .=1.89, \quad h=0.79 \text {. }
$$

\footnotetext{
${ }^{4}$ For details on the ADF test, see Enders (1995).

${ }^{5}$ The $t$ statistics significant at 5 percent and 10 percent levels are indicated by $*$ and ** respectively.
} 
As can be seen, the explanatory power of the model is reasonably good. Autocorrelation is absent and the results are not eroded by multicollinearity as judged by its symptoms. The regression coefficients are statistically significant and their signs are consistent with theory.

The results suggest that one percent increase in the price level of import, whether due to exchange rate devaluation or the rising world prices, results in 0.15 percent increase in CPI. Since this is the impact period effect realised within one quarter and the lagged as well as feed-back effects are separately controlled, one can expect the contribution of imported inflation to be close to the share of imports in gross domestic expenditure. Incidentally this share happens to be 15.7 percent over the estimation period, close to the estimated impact period elasticity.

The impact period effect of one percent growth in money supply on CPI is 0.07 percent which is lower than one would expect. The reason could be that one quarter is too short a time period to have the effect of monetary expansion on the price level fully realised because of the slow process through which economy responds to the shock. On the other hand the impact period elasticity of CPI with respect to real GDP, estimated at -0.21 , is relatively high.

The results show that strong inertia is present in inflation rate as more than half of the inflation in the current quarter is carried on to the next quarter. If, for example, CPI increases by one percent in the current quarter then holding other things constant, CPI would increase by 0.51 percent in the next quarter, by 0.26 percent after two quarters, 0.13 percent after three quarters, 0.07 percent after four quarters and so on. Further more significant seasonality is also present in CPI as 35 percent of inflation in any quarter is transmitted to the same quarter of the next year.

In the exchange rate equation the impact period elasticity of exchange rate with respect to domestic price level is estimated to be 0.34 , while the elasticity of exchange rate with respect to the world price level is -0.18 . Thus exchange rate responds more actively to domestic price level than to the world price level and PPP fails to hold in the short run. In other words, the pressure to devalue Pakistani rupee in response to domestic inflation is much stronger than the pressure resulting from reduced world prices.

The relationship of exchange rate with foreign exchange reserves shows that if, for example, the level of foreign exchange reserves doubles, the nominal exchange rate would appreciate by 1.3 percent within a quarter.

Like in the price equation, strong inertia is also present in the exchange rate equation. The results show that, holding other things constant, one percent devaluation in a quarter leads to another devaluation by 0.67 percent in the following quarter, 0.44 percent after two quarters, 0.29 percent after three quarters, 0.20 percent after four quarters and so on.

The results also show that the impact period elasticity of exchange rate with 
respect to price level is more than twice the elasticity of price level with respect to exchange rate. ${ }^{6}$ This means that, while both the exchange rate and general price level affect each other, in the short run inflation can be more of a cause of devaluation than its result.

Considering the current feedback effects in price level and exchange rate, one can imagine that the presence of inertia in both the variables and seasonality in price level would produce strong dynamics through which the effects of various shocks are transmitted to price level and the exchange rate. We now conduct a simulation exercise to trace these dynamics.

\section{DYNAMIC SIMULATIONS}

Although we have drawn a number of useful results so far, we are yet to analyse the short run movements in price level and exchange rate as they get displaced from their long run paths. The dynamic properties of the relationship between price level and exchange rate can be studied by introducing various shocks in the model and tracing the time paths of the resulting changes in price level and exchange rate over some length of time.

We consider two types of shocks: temporary and permanent. In order to concentrate on the effects of a particular shock under consideration, we assume that no other shocks occur over a certain length of time and that initially both the price level and exchange rate are historically given. For each of the temporary and permanent shocks we shall consider one by one: monetary shock, output shock, import price shock, export price shock and foreign reserves shock. A temporary shock is introduced by changing the relevant variable by one percent in period 1 , while assuming that the other exogenous variables are constant and no further shock occurs in the subsequent periods. For a permanent shock the concerned variable is changed permanently by one percent from the period 1 onwards. In both cases the resulting changes in price level and exchange rate are expressed in percentage terms.

The results of simulation are presented in Figure 1 . Consider first the monetary shock. Since money supply is changed by one percent and the coefficient of money supply variable in the price equation is 0.067 , its immediate and direct effect is that the price level increases by 0.067 percent. The exchange rate also changes by 0.341 (the coefficient of price variable in the exchange rate equation) times the change in price level, that is by $0.341 \times 0.067=0.0228$ percent. Including the current period feed-back effects between price level and exchange rate, the impact period effects of the given monetary shock on the price level and exchange rate are estimated at 0.071 percent and 0.024 percent respectively.

${ }^{6}$ This result is quite robust in the sense that the relevant estimates remain stable across all the estimated equations, which we have not reported in the paper. 

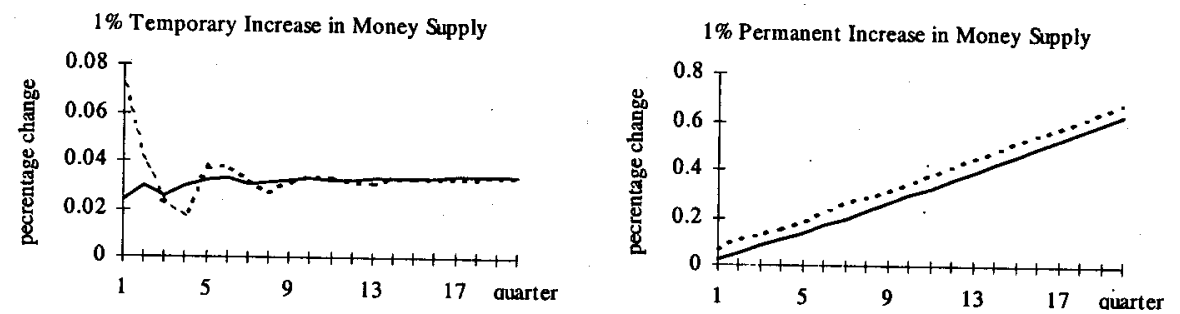

$1 \%$ Temporary Increase in Real GDP
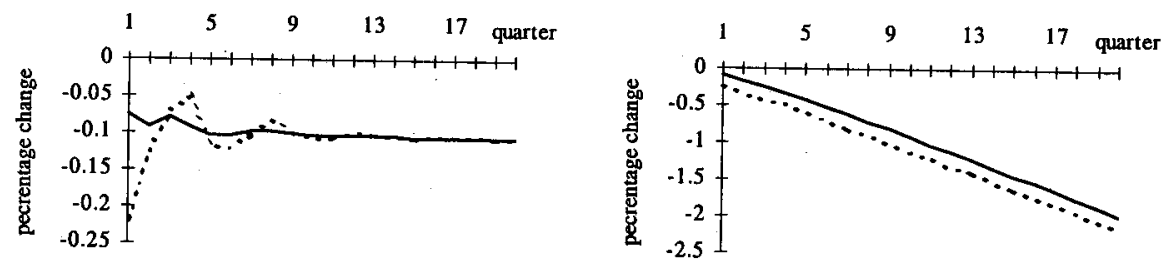

$1 \%$ Temporary Increase in \$ Price of Imports
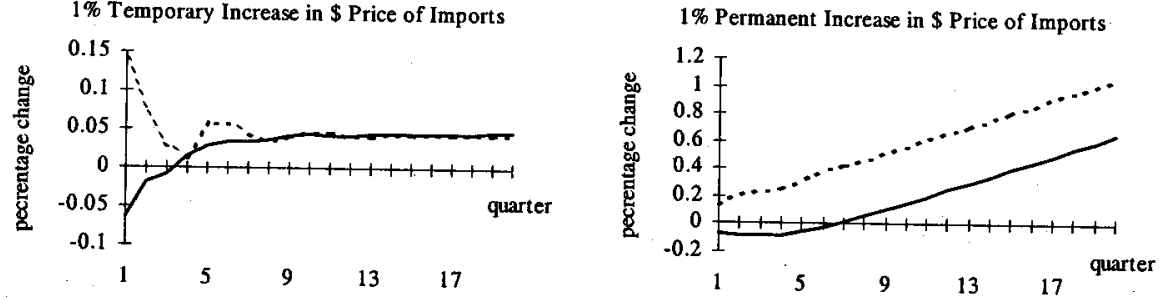

$1 \%$ Temporary Increase in \$ Price of Exports
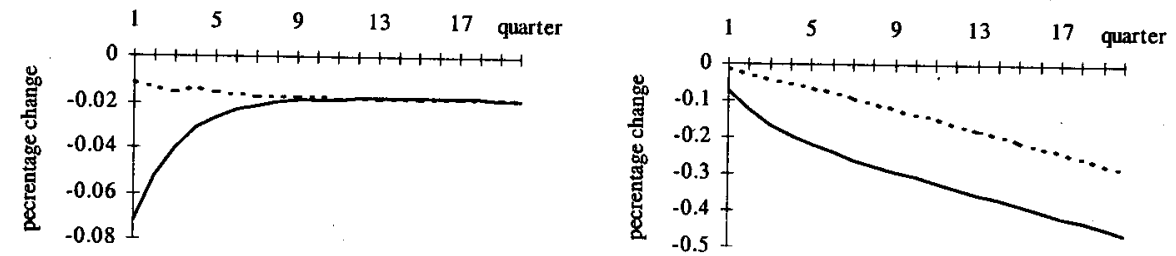

$1 \%$ Temporary Increase in Foreign Reserves
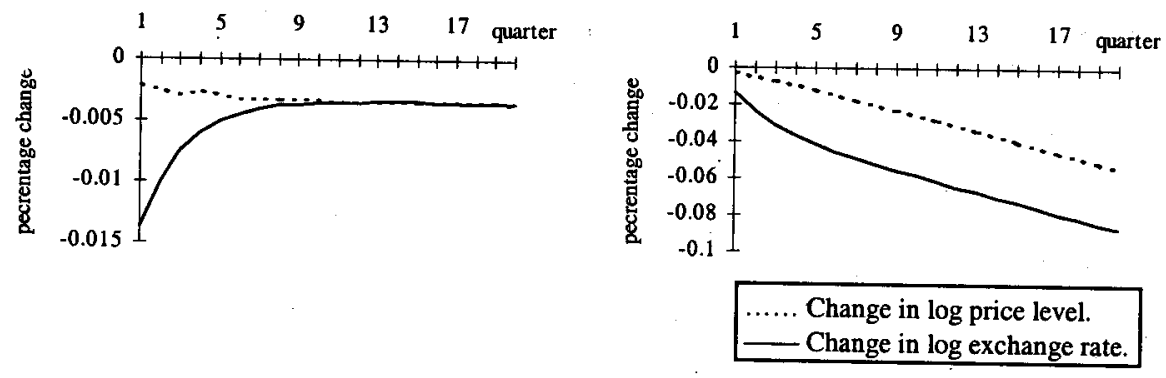

Fig. 1. Effects of Shocks on Price Level and Exchange Rate. 
In period 2 no further monetary shock occurs. The price level, however, rises through inertia in price level itself and due to the change in the exchange rate that too follows its past trend. Likewise, the exchange rate in period 2 also rises. The increase in price level in period 2 is smaller than in period 1 because of the obvious reason that the monetary shock had occurred in period 1 only while its inflationary effect in period 2 is secondary. On the other hand, the rate of exchange rate depreciation in period 2 is more than the rate in period 1. This can be explained as follows: Devaluation in period 1 is caused by the inflation resulting from monetary shock only and the impact period effect of inflation on exchange rate is a small fraction of inflation rate. In period 2 exchange rate is devalued not only due to continuing inflation, though at a reduced rate, but also on account of inertia in exchange rate itself. These two effects combined produce a stronger pressure for devaluation as compared to the initial pressure.

In periods 3 and 4 almost the same trend continues and the rates of change in both price level and exchange rate tend to stabilise. In period 5, however, the seasonal pattern in price level emerges and produces another mini shock. What happens in periods 6 to 8 should be obvious.

In the subsequent periods as time passes, the rates of change in the price level and exchange rate not only stabilise but also tend to coincide with each other. Also noticeable is the observation that monetary expansion in period 1 by one percent produces a mild but permanent rate of inflation and exchange rate devaluation by 0.034 percentage point.

It is obvious from the above results that in the short run the PPP equation does not hold. But the evidence supports the proposition that in the long run the rates of inflation and exchange rate devaluation are equalised and the PPP equation holds in relative terms.

The effect of a permanent increase in money supply in period 1 is obviously identical to the effect of temporary shock discussed in the foregoing. In period 2, besides the lagged effects of the shock, price level and exchange rate also rise due to an additional increase in money supply. With an accumulated effect, the changes in price level follow a relatively smooth rising trend, especially during the later period of simulation, for the following reasons: First, the fluctuating lag effects are smaller than the persistent impact period effects of fresh monetary injections. Second, as we move further into the future, the accumulated lag effects tend to stabilise. Likewise, the rate of exchange rate depreciation also follows a smooth trend. The results show that continuous monetary expansion by one percent in each quarter produces an inflation rate of about 0.68 percent and devaluation of exchange rate by 0.63 percent after five years.

It may be noticed that over the periods the inflation rate remains above the rate 
of exchange rate devaluation by almost a fixed margin. The reason is that the impact period effects of continuous monetary shocks in each period are more pronounced on the price level than on the exchange rate. Thus a constant divergence from the PPP equation is maintained even in the long run. This result lends support to the conclusion that the persistent shocks of similar magnitude tend to dilute the PPP equation in the following sense. A temporary monetary shock disturbs the PPP equation in the short run but in the long run parity holds in relative sense, that is, in the absence of world inflation, both the domestic inflation rate and the percentage change in exchange rate converge to a single value. If, however, the shocks persist over a long period of time, only the marginal changes in inflation rate and the rate of exchange rate devaluation are equalised in the long run. That is, the PPP equation holds even in a weaker form.

The time paths of changes in price level and exchange rate following the temporary and permanent output shocks are the mirror images of the paths under the monetary shocks except for the difference in scale. The reason is that the direct effects of an output shock on price level and exchange rate are opposite but larger in size as compared to the effects of monetary shock.

We now discuss the external shocks. The impact period effects of an import price shock can be explained by referring to the estimated coefficients of the import price and world price variables $\Pi_{m}$ and $\Pi_{w}$ and the feedback effects between the two equations. The price level is positively related to import price level while exchange rate is inversely related to it. Since these direct effects dominate the feedback effects, the net result is that the price level rises while the exchange rate declines.

In the second period inflation rate is still positive due to strong price inertia but in the absence of any additional shock, the rate of inflation in this period declines. The rate of appreciation in exchange rate also declines in period 2 for similar reasons. In the subsequent periods, this trend continues, except for the seasonal shocks popping up after every four quarters. The effect of positive inflation on exchange rate outweighs the influence of inertia from period 4 onwards and the exchange rate starts depreciating.

Simulation results for the permanent import price shock show that exchange rate appreciates due to the impact period effects of continuing shocks as well as on account of the lag effects of temporary shocks for up to three quarters. Since the permanent shock is the accumulation of continuing temporary shocks, the above pattern translates into a declining exchange rate for up to six quarters following the permanent shock. Thereafter the exchange rate starts rising. There is no such reversal of trend in inflation rate and it continues to rise from the very outset. However, within two years both the exchange rate and price level assume smooth rising trends and the disparity between the rates of growth in the two variables also converges to a constant value (about 0.4 ). 
Simulation results for the temporary export price shock show that the increase in export price produces favourable effects both on the price level and exchange rate. However in the impact period the resulting improvement in exchange rate is more significant than the improvement in the price level because the exchange rate is affected directly by the shock whereas the effect on price level is indirect, through the appreciation of exchange rate. From period 2 onwards the rate of appreciation in exchange rate continues to decline at a diminishing rate in the absence of any additional shocks. Since the direct effect of the shock is on exchange rate, the changes in inflation rate remain fairly stable from the very outset. Again both the rates of decrease in exchange rate and price level tend to stabilise and coincide with the passage of time.

The permanent export price shock shows that both the rates of deflation and exchange rate appreciation continue to rise due to persistent increase in export prices. But the rate of appreciation in exchange rate remains more than the rate of decrease in inflation rate.

The results of simulation for the effects of temporary and permanent growth in foreign exchange reserves are qualitatively similar to the results for export price shock, except for the differences in scales. The reason is that in both cases, the shock primarily results in exchange rate appreciation while its inflationary effect is secondary.

We draw three main conclusions from the above exercise. First, the impact period effects of temporary shock on the price level and exchange rate are divergent, while the long run effects are convergent. This means that, while the PPP proposition does not hold in the short run, there is a tendency in the system to regain the parity in the long run. Second, the continuation of shocks can produce a persistent but nonaccelerating divergence between inflation rate and the rate of devaluation. That is, the PPP equation holds for the marginal changes in the rates of changes in price level and exchange rate over time. Third, the direction of temporary disparity between the rates of inflation and devaluation depends crucially on the origin of the shock. The shocks with direct effect on price level (exchange rate) have more pronounced effects on the rate of inflation (devaluation).

\section{CONCLUDING REMARKS}

This study shows that the relationship between price level and exchange rate is not unidirectional, though the short run effect of devaluation on inflation is estimated to be smaller than the effect of inflation on devaluation. The presence of significant feedback effects and strong dynamics in the model suggest that the relationship between price level and exchange rate is too complex to be fully understood by just estimating a model and observing the size and statistical significance of regression coefficients. It is essential to analyse the transitionary phase of price level and exchange rate 
movements as they get displaced from their respective long run paths due to various shocks. We considered five different types of temporary as well as permanent shocks. The two domestic shocks considered are monetary and real shocks, while the three external shocks are import price, export price and foreign exchange reserves shocks. A simulation experiment on these lines led to the following conclusions:

While in the short run the Purchasing Power Parity (PPP) proposition does not hold, the dynamic response to temporary shocks allow the system to adjust gradually to regain the parity in relative sense. That is, the PPP holds for the marginal changes in the price level and exchange rate so that for the given world prices, the inflation rate is equalised with the rate at which the exchange rate depreciates.

If the shocks continue to occur on a regular basis over a long period of time, they can prevent the stabilising forces from making a complete adjustment towards the PPP equation. The sluggishness in adjustment mechanism results in a persistent but non-accelerating disparity between the inflation rate and the rate of devaluation, thereby placing PPP at a weaker position. In this case PPP holds for the marginal changes in the rates of growth (rather than the levels) in the price level and the exchange rate.

The size of divergence between the rates of inflation and devaluation depends crucially on the origin of the shock. Since the domestic (monetary and real) shocks exert predominant direct effects on price level as opposed to exchange rate, they would produce larger variations in price level than in exchange rate. The same hold in case of import price shock because its direct favourable effect on exchange rate is more than offset by devaluation due to the inflationary effect of the shock. The export price and foreign reserve shocks, on the other hand, result in larger variation in exchange rate than in the price level because the exchange rate is exposed to these shocks from the very outset.

We also conclude that since movements in exchange rate are mostly driven by price inflation, the practice of managing exchange rate as an independent instrument is not sustainable in the presence of inflation. From the policy perspective both the inflation and exchange rate could be considered as interrelated targets while focusing on the instruments that are in effective control of policy-makers. One such instrument that can make the difference is money supply. Thus a consistently followed tight monetary policy is the key. Unless consistency is maintained, the gains would be temporary only and the monetary shocks will continue to produce inflation and in turn devaluation of the rupee. Since alternative measures to achieve various objectives can produce conflicting results, a strict discipline and coordination is essential for the effectiveness of policies. 


\section{REFERENCES}

Ahmad, E., and H. Ram (1991) Foreign Price Shocks and Inflation in Pakistan: A Monetarist Approach. Pakistan Economic and Social Review 29:1 1-20.

Attfield, C. L. F., D. Demery, and N. W. Duck (1981) A Quarterly Model of Unanticipated Monetary Growth, Output and the Price Level in the U. K. Journal of Political Economy 8: 331-350.

Bhatti, R. H. (1996) A Correct Test of the Purchasing Power Parity: The Case of Pak-

Rupee Exchange Rates. The Pakistan Development Review 35:4 671-682.

Bilquees, F. (1988) Inflation in Pakistan: Empirical Evidence on the Monetarist and Structuralist Hypothesis. The Pakistan Development Review 27:2 109-130.

Branson, W. H. (1978) Exchange Rate Dynamics and Monetary Policy. In Assar

Linbeck (ed.) Inflation and Employment in Open Economies. The Netherlands:

North Holland Publishing Company. pp. 189-224.

Burney, N. A., and N. Akhtar (1992) Government Budget Deficit and Exchange Rate Determination: Evidence from Pakistan. The Pakistan Development Review 31:4 871-82.

Cooper, J. C. B. (1994) Purchasing Power Parity: A Cointegration Analysis of the Australian, New Zealand and Singaporean Currencies. Applied Economics Letters 1: 167-171.

Crowder, W. J. (1992) Purchasing Power Parity Over the Modern Float: An Application of Higher Order Cointegration. Economics Letters 40: 313-318.

Dornbusch, R. (1981) Monetary Policy Under Exchange Rate Flexibility. In Robert E.

Baldwin and Richardson J. David (eds.) International Trade and Finance, Readings. Boston: Little, Brown and Company.

Enders, W. (1995) Applied Econometric Time Series. New York: John Willy and Sons Inc. 221-2234.

Hassan, M. A., and A. H. Khan (1994) Impact of Devaluation on Pakistan's External

Trade: An Econometric Approach. The Pakistan Development Review 33:4 12051215.

Isard, P. (1983) An Accounting Framework and Some Issues for Modeling How Exchange Rate Responds to the News. In J. A. Frenkel (ed.) Exchange Rates and International Macroeconomics. National Bureau of Economic Research. 19-65.

Khan, A. H., and M. A. Qasim (1996) Inflation in Pakistan Revisited. The Pakistan Development Review 35:4 747-757.

Kormendi, R. C., and P. G. Meguire (1984) Cross-Regimes Evidence of Macroeconomic Rationality. Journal of Political Economy 92: 875-908.

Krugman, P. R., and M. Obstfield (1992) Price Level and Exchange Rate in the Long Run. In P. R. Krugman and M. Obstfield International Economics: Theory and Policy. Reading, Massachusetts: Scott Forman \& Co. 398-432. 
Mahmood, Z., R. Siddiqui, and U. Afridi (1996) Exchange Rate Determination in Pakistan: A Simultaneous Equation Model. The Pakistan Development Review 35:4 537-548.

Nachane, D. M., and A. Chrissanthaki (1991) Purchasing Power Parity in the Short and Long Run: A Reappraisal of the Post-1973 Evidence. Applied Economics 23: 12571268.

Sodersten, B., and G. Reed (1994) Macroeconomic Policy with Fixed and Pegged Exchange Rates. In Bo Sdersten and Geoffrey Reed (eds) International Economics. Third Edition. Houndmills, Basingstoke: The MacMillan Press Ltd. 613-641.

Sodersten, B., and G. Reed (1994a) The Determination of a Floating Exchange Rate. In Bo Sdersten and Geoffrey Reed (eds) International Economics. Third Edition, Houndmills, Basingstoke: The MacMillan Press Ltd. 571-595.

Turnorsky, S. J., and A. Kaspura (1974) An Analysis of Imported Inflation in a Short Run Macroeconomics Model. Canadian Journal of Economics 7. 